\title{
Primary dystonia, DYT6 type
}

INSERM

\section{Source}

INSERM. (1999). Orphanet: an online rare disease and orphan drug data base. Primary dystonia, DYT6 type. ORPHA:98806

Primary dystonia DYT 6 type is characterized by focal, predominantly cranio-cervical dystonia with dysarthria and dysphagia, or limb dystonia in some cases. 